\title{
Synthesis, Structural and Luminescence Studies of Europium Doped Borate Glasses
}

\author{
V L Usharani, B Eraiah \\ Department of Physics, Bangalore University, Bengaluru-560056, Karnataka, India \\ E-mail: eraiah@rediffmail.com (Corresponding author)
}

Received: 23 March 2020; Accepted: 16 April 2020; Available online: 30 April 2020

\begin{abstract}
Different concentration of $(0.1,0.2,0.3,0.4,0.5,1.0$ \& 1.5) mol\% of europium doped lead borate lithium glasses were prepared by melt quenching method. The properties of thermal, photoluminescence \& structural were analyzed using DTA, FTIR and emission spectra. Emission spectra was used to evaluate the JuddOfelt (JO) parameters. Radiative parameters like stimulated emission cross-sections $\left(\sigma_{\mathrm{e}}\right)$, effective band width $\left(\Delta \lambda_{\text {eff }}\right)$, transition probabilities (A), optical gain bandwidths $\left(\sigma_{\mathrm{e}} \mathrm{x} \Delta \lambda_{\text {eff }}\right)$, radiative lifetime $\left(\tau_{\text {rad }}\right)$ and optical gain $\left(\sigma_{e}\right.$ $\left.\mathrm{x} \tau_{\text {rad }}\right)$ values were evaluated for the transition ${ }^{5} \mathrm{D}_{0} \rightarrow{ }^{7} \mathrm{~F}_{\mathrm{j}}(\mathrm{j}=1,2,3$ and 4$)$ of $\mathrm{Eu}^{3+}$ ions. The outcome of transition ${ }^{5} \mathrm{D}_{0} \rightarrow{ }^{7} \mathrm{~F}_{4}$ at its highest value of branching ratios and stimulated emission cross-section are evaluated with the literature. Hence we can could the prepared host glass doped with $\mathrm{Eu}^{3+}$ ions are good fibre amplifiers and it can be used as a red laser.
\end{abstract}

Keywords: Borate glasses; Radiative parameters; Time-decay; Transition probabilities.

\section{Introduction}

Glasses doped with RE ions are of larger interest due to their use in infrared-to-visible up-converters, solidstate lasers, bulk lasers, waveguide lasers, planar waveguides, temperature sensors, flat panel displays, field emission displays, optical fiber amplifiers, high-density memory devices, high-density frequency domain optical data storage, color display devices and electroluminescent devices [1-3]. Among all RE ions, europium is a unique component because of the divalent or trivalent valence state. Photonic applications are used $\mathrm{Eu}^{3+}$ ion due to its property of red light emission, which was observed during the transition ${ }^{5} \mathrm{D}_{0}----{ }^{7} \mathrm{~F}_{2}$ state and it is very sensitivity to minute changes when surrounded by chemicals. The emission from non-degenerate ${ }^{5} \mathrm{D}_{0}$ to ${ }^{7} \mathrm{~F}_{\mathrm{j}}(\mathrm{j}=0-6)$ levels gives site symmetry around active ions and number of sites available for active ions [4-7].

\section{Experimental studies}

The raw chemicals $\mathrm{Eu}_{2} \mathrm{O}_{3}, \mathrm{Li}_{2} \mathrm{CO}_{3}, \mathrm{PbO}, \mathrm{H}_{3} \mathrm{~B}$ are used as starting materials to synthesise the new glass serious, i.e., europium doped lithium lead borate glasses by conventional melt quenching technique is described elsewhere. The prepared glass samples are named as ELPB0, ELPB1, ELPB2, ELPB3, ELPB4, ELPB5, ELPB6 \& ELPB7 for the concentration of $\mathrm{Eu}_{2} \mathrm{O}_{3}$ i.e., $0,0.1,0.2,0.3,0.4,0.5,1.0 \& 1.5$ respectively.

Archimedes principle were used to calculate the densities of the prepared glass samples. From room temperature to $900{ }^{\circ} \mathrm{C}$ DTA measurement were carried out in nitrogen atmosphere with a resolution of $1 \mathrm{ml}$ min-1 using Perkin Elmer STA 6000. From KBR pellet technique FTIR spectra (350 - 3500) are recoded using Thermo Nicolet Avata 370. Using Shimadzu spectrophotometer UV-1800 (250 - $1200 \mathrm{~nm})$, the optical absorption spectra were recorded. Photoluminescence and time decay characterization are done using Horiba Fluorolog spectrofluorometer with 450Wxenon lamp as excitation source.

\section{Results and discussions}

\subsection{Optical studies}

The optical absorption spectra were shown in Fig. 1 it consists of three peaks the transitions are from ${ }^{7} \mathrm{~F}_{0}$ to ${ }^{5} \mathrm{~L}_{6}$, ${ }^{5} \mathrm{D}_{2} \&{ }^{5} \mathrm{D}_{1}$ at 393, 464 and $525 \mathrm{~nm}$ wavelengths. All these transitions are well agreeing with the pervious literature [8,9]. Compare to all transitions ${ }^{7} \mathrm{~F}_{0} \rightarrow{ }^{5} \mathrm{~L}_{6}$ is more intense because of well population region. As the Eu ${ }^{3+}$ concentration increases, the absorption peak intensity is increasing and no peak shift is observed. This is evidence 
for the RE dissolvable in the glass matrix. By Mott and Davis calculation the indirect and direct energy band gaps were expected [10]

$$
\alpha(h v)=B\left(h v-E_{\text {opt }}\right)^{n}
$$

where $\alpha$ represents absorption coefficient, hv represents IPE (incident photon energy), B represents a constant, $\mathrm{E}_{\mathrm{opt}}$ represents OEBG (optical energy band gap) and n represents the number which expresses the transition processes. Irregular variation is observed in both indirect and direct energy band gap values with the increase of $\mathrm{Eu}_{2} \mathrm{O}_{3}$ concentration, this may be due to the changes occurring in bonds and also due to the photon-lattice interaction [11]. Optical parameters which are calculated in this paper are tabulated in table 1 and the variation are shown in Fig.2 \&3. Fig. $2 \& 3$ are the plot of density v/s molar volume and oxide ion polarizability v/s optical basicity with respect to the $\mathrm{Eu}_{2} \mathrm{O}_{3}$ concentration respectively. Non-bridging oxygen's are found due to the addition of $\mathrm{Eu}_{2} \mathrm{O}_{3}$ concentration to the host ELPB glass matrix which resulted in variation of all the optical parameters. NA (Numerical aperture) values of the prepared glass samples are between $0.3-0.4$, if the NA values are between 0.13 0.5 such glasses are recommended as primary raw material for creation of optical fibres. To summarized our recommendation is to use the prepared glass samples as a primary raw material in creation of optical fibres as they absorb light from the sources [12].

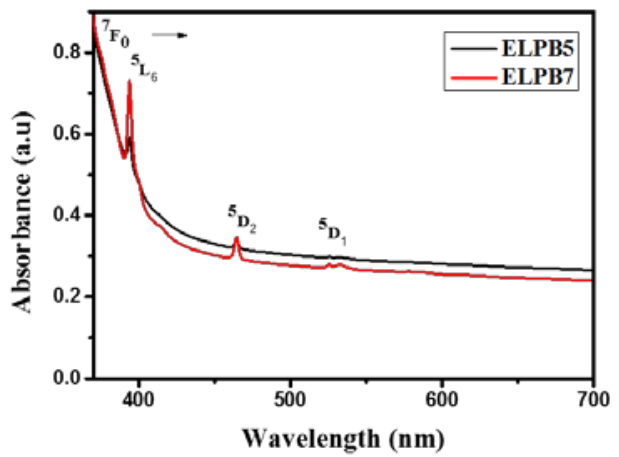

Figure 1. Optical absorption spectra of ELPB glasses with $0.5 \mathrm{~mol} \%$ and $1.5 \mathrm{~mol} \%$ of $\mathrm{Eu}_{2} \mathrm{O}_{3}$ concentrations

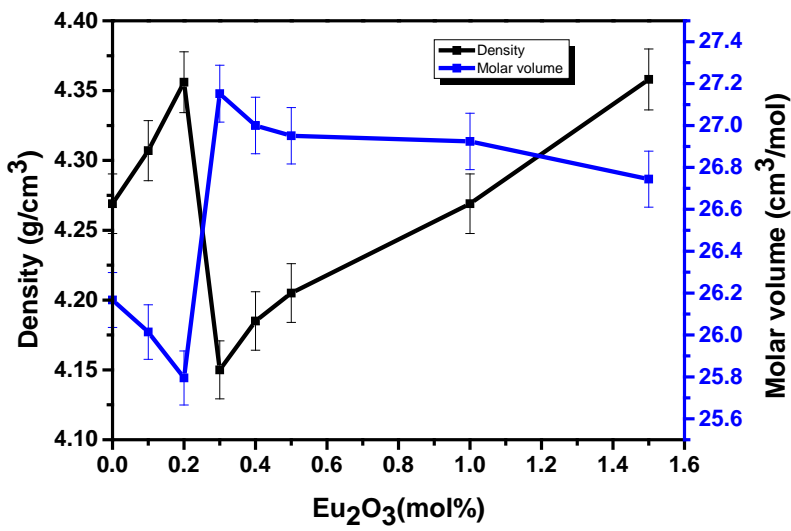

Figure 2. Density and molar volume with the $\mathrm{Eu}_{2} \mathrm{O}_{3}$ concentrations

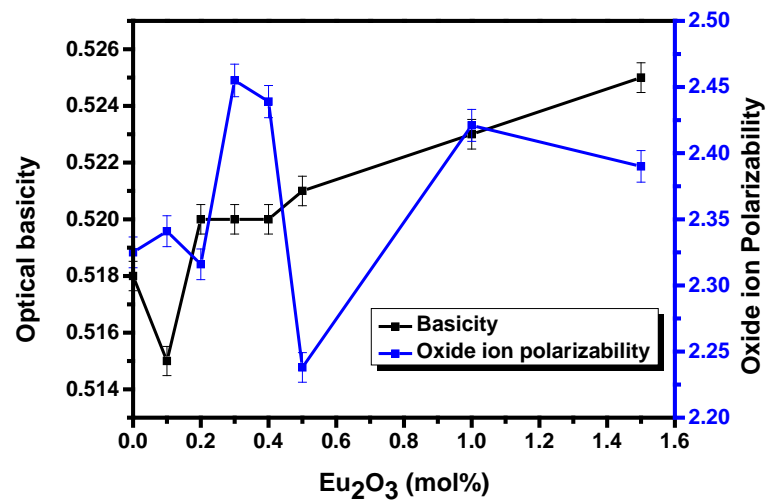

Figure 3. Optical basicity and Oxide ion polarizability with the $\mathrm{Eu}_{2} \mathrm{O}_{3}$ concentrations 
Table 1. Density $\rho\left(\mathrm{g} / \mathrm{cm}^{-3}\right)$, molar volume $V_{m}\left(\mathrm{~cm}^{3} / \mathrm{mol}\right)$, refractive index, direct energy band gap $\left(E_{g}{ }^{d}\right)$, indirect energy band gap $\left(\mathrm{Eg}_{\mathrm{g}}^{\mathrm{i}}\right)$, molar refraction $\left(\mathrm{R}_{\mathrm{m}}\right)$, molar polarizability $\left(\alpha_{\mathrm{m}}\right)$, refection loss $\left(\mathrm{R}_{\mathrm{L}}\right)$, dielectric constant $(\varepsilon)$, optical basicity $(\Lambda)$, electric polarizability of oxide ions $\left(\alpha^{02-}\right)$, electronegativity $(\chi)$, electric susceptibility $\left(\chi_{e}\right)$ and numerical aperture (N A)

\begin{tabular}{lllllllll}
\hline $\begin{array}{l}\text { Physical } \\
\text { parameters }\end{array}$ & ELPB0 & ELPB1 & ELPB2 & ELPB3 & ELPB4 & ELPB5 & ELPB6 & ELPB7 \\
$\rho \rho \pm 0.001$ & 4.269 & 4.307 & 4.356 & 4.150 & 4.185 & 4.205 & 4.269 & 4.358 \\
$\mathrm{~V}_{\mathrm{m}} \pm 0.001$ & 26.167 & 26.014 & 25.795 & 27.152 & 27.000 & 26.951 & 26.924 & 26.744 \\
$\mathrm{R} . \mathrm{I} \pm 0.001$ & 2.33 & 2.368 & 2.370 & 2.365 & 2.368 & 2.374 & 2.376 & 2.380 \\
$\mathrm{E}_{\mathrm{g}}$ (direct) \pm 0.001 & 3.158 & 3.116 & 3.127 & 3.03 & 3.100 & 3.179 & 3.346 & 3.125 \\
$\mathrm{E}_{\mathrm{g}}$ (indirect) \pm 0.001 & 2.771 & 1.839 & 2.572 & 1.461 & 2.673 & 2.250 & 2.676 & 2.596 \\
$\mathrm{R}_{\mathrm{m}} \pm 0.001$ & 15.648 & 15.755 & 15.635 & 16.425 & 16.353 & 16.342 & 16.339 & 16.276 \\
$\alpha_{\mathrm{m}} \pm 0.001$ & 6.209 & 6.252 & 6.204 & 6.518 & 6.489 & 6.485 & 6.484 & 6.459 \\
$\mathrm{R}_{\mathrm{L}} \pm 0.001$ & 15.952 & 16.498 & 16.526 & 16.455 & 16.498 & 16.584 & 16.612 & 16.670 \\
$\varepsilon \pm 0.001$ & 5.461 & 5.607 & 5.617 & 5.593 & 5.607 & 5.636 & 5.645 & 5.664 \\
$\Lambda \pm 0.001$ & 0.518 & 0.515 & 0.520 & 0.520 & 0.520 & 0.521 & 0.523 & 0.525 \\
$\alpha^{02-} \pm 0.001$ & 2.325 & 2.341 & 2.316 & 2.455 & 2.439 & 2.438 & 2.421 & 2.390 \\
$\chi \pm 0.0001$ & 0.9409 & 0.9361 & 0.9430 & 0.9428 & 0.9433 & 0.9441 & 0.9468 & 0.9495 \\
$\chi_{\mathrm{e}} \pm 0.0001$ & 0.355 & 0.3668 & 0.3676 & 0.3657 & 0.3668 & 0.3691 & 0.3698 & 0.3714 \\
$\mathrm{NA} \pm 0.001$ & 0.330 & 0.334 & 0.335 & 0.335 & 0.335 & 0.336 & 0.337 & 0.338 \\
\hline
\end{tabular}

\subsection{Thermal analysis}

The characteristic temperatures of any glass like melting temperature, crystallization temperature and transition temperature are evaluated by Differential thermal analysis [13]. The ELPB0 and ELPB1 glasses, DTA curves obtained at the heating rate of $10^{\circ} \mathrm{C} / \mathrm{min}$ are depicted in Figs. 4 (a) and (b). All thermal parameters were determined and are given in table 2, in the range of $442-470{ }^{\circ} \mathrm{C}$ are the glass transition temperature of the prepared glass samples. From the onset crystallization $\left(\mathrm{T}_{\mathrm{c}}\right)$ and glass transition temperature $\left(\mathrm{T}_{\mathrm{m}}\right)$ of the glasses, the thermal stability was determined [14]. GFA (Glass forming ability) K is determined by the relation given by Hruby [15]. The thermal stability is determined based on the relation provided by Saad and Poulin [16]. To summarize this samples output are recommended for fibre fabrication due to its phenomenon thermal stability.

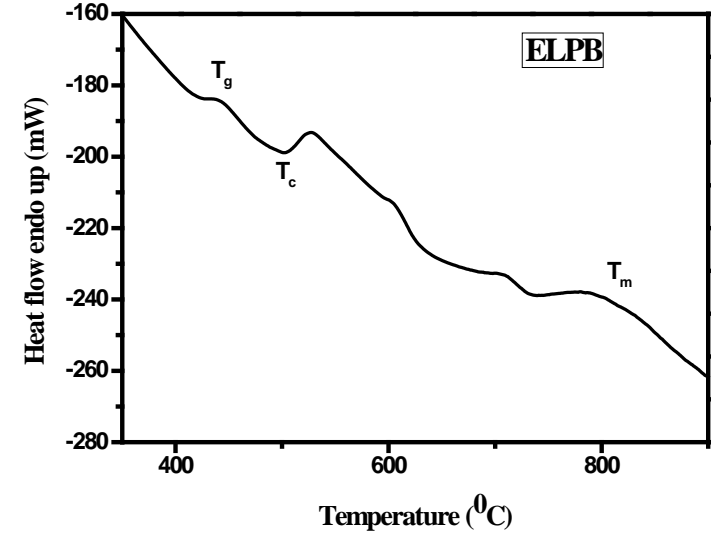

Figure 4(a). Glass transition temperature with temperature of ELPB glass

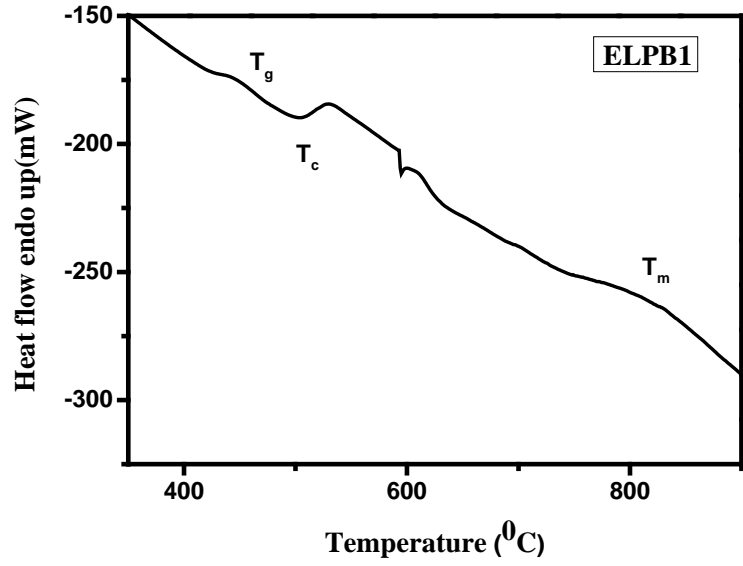

Figure 4(b). Glass transition temperature with temperature of ELPB1 glass

\subsection{FTIR analysis}

FTIR spectra of $\mathrm{Eu}^{3+}$ doped and undoped ELPB glasses were recorded in the range of $350-3500 \mathrm{~cm}^{-1}$ wavenumber, both doped and undoped spectra are having same spectral features, which is shown in Fig. 5 . The spectrum consists of five bands at $691 \mathrm{~cm}^{-1}, 980 \mathrm{~cm}^{-1}, 1370 \mathrm{~cm}^{-1}, 2358 \mathrm{~cm}^{-1} \& 3408 \mathrm{~cm}^{-1}$. The band $2358 \mathrm{~cm}^{-1} \&$ $3408 \mathrm{~cm}^{-1}$ identifies the existence of $\mathrm{O}-\mathrm{H}$ stretching vibration. Asymmetric $\mathrm{B}-\mathrm{O}$ stretching vibration mode of $\mathrm{BO}_{3}$ trigonal units for the band $1370 \mathrm{~cm}^{-1}$. At around the band $980 \mathrm{~cm}^{-1}$ is witnessed due to $\mathrm{B}-\mathrm{O}$ stretching vibration of $\mathrm{BO}_{4}$ tetrahedral unit. The absorption band at $691 \mathrm{~cm}^{-1}$ is the collective vibration of $\mathrm{BO}_{4} \& \mathrm{PbO}_{4}$ groups respectively [17 -19]. 
Table 2. Glass transition temperature $\left(T_{g}\right)$, Crystallization temperature $\left(T_{c}\right)$, onset crystallization temperature $\left(T_{p}\right)$, Melting temperature $\left(\mathrm{T}_{\mathrm{g}}\right)$, thermal stability $\left(\mathrm{T}_{\mathrm{c}}-\mathrm{T}_{\mathrm{g}}\right)$, reduced glass transition temperature $\left(\mathrm{T}_{\mathrm{rg}}\right)$, glass forming ability $(\mathrm{K})$ and thermal stability parameter $(\mathrm{S})$

\begin{tabular}{lllllllll}
\hline $\mathrm{x}(\mathrm{mol} \%)$ & $\begin{array}{l}\mathrm{T}_{\mathrm{g}}\left({ }^{0} \mathrm{C}\right) \\
\pm 1\end{array}$ & $\begin{array}{l}\mathrm{T}_{\mathrm{c}}\left({ }^{0} \mathrm{C}\right) \\
\pm 1\end{array}$ & $\begin{array}{l}\mathrm{T}_{\mathrm{p}}\left({ }^{0} \mathrm{C}\right) \\
\pm 1\end{array}$ & $\begin{array}{l}\mathrm{T}_{\mathrm{m}}\left({ }^{0} \mathrm{C}\right) \\
\pm 1\end{array}$ & $\begin{array}{l}\left(\mathrm{T}_{\mathrm{c}}-\mathrm{T}_{\mathrm{g}}\right) \\
{ }^{0} \mathrm{C}\end{array}$ & $\begin{array}{l}\mathrm{T}_{\mathrm{rg}}\left({ }^{0} \mathrm{C}\right) \\
\pm 0.01\end{array}$ & $\begin{array}{l}\mathrm{K}\left({ }^{0} \mathrm{C}\right) \\
\pm 0.001\end{array}$ & $\begin{array}{l}\mathrm{S}\left({ }^{0} \mathrm{C}\right) \\
\pm 0.05\end{array}$ \\
\hline 0 & 439 & 505 & 590 & 788 & 66 & 0.557 & 0.230 & 12.78 \\
0.1 & 442 & 504 & 594 & 807 & 62 & 0.547 & 0.205 & 12.62 \\
0.2 & 443 & 506 & 599 & 813 & 63 & 0.545 & 0.208 & 13.23 \\
0.3 & 446 & 510 & 606 & 817 & 64 & 0.549 & 0.202 & 13.77 \\
0.4 & 449 & 512 & 611 & 823 & 63 & 0.550 & 0.203 & 13.89 \\
0.5 & 453 & 515 & 617 & 821 & 62 & 0.556 & 0.208 & 13.96 \\
1.0 & 460 & 524 & 621 & 831 & 64 & 0.557 & 0.215 & 12.54 \\
1.5 & 468 & 533 & 627 & 835 & 65 & 0.560 & 0.17 & 12.60 \\
\hline
\end{tabular}

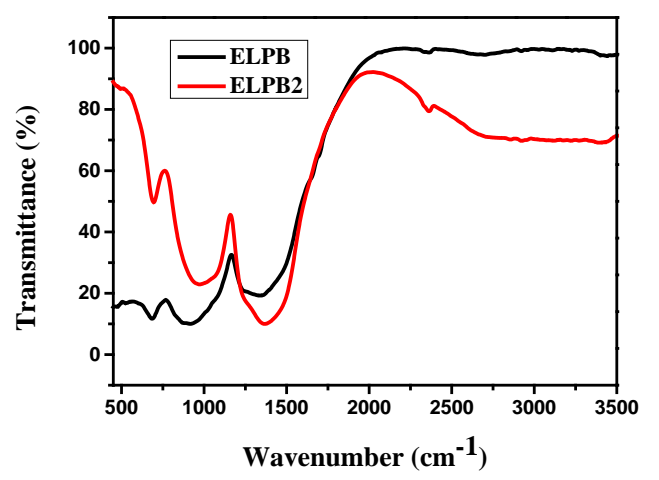

Figure 5. FTIR spectra of ELPB and ELPB2 glasses

\subsection{Fluorescence studies}

The emission spectra of ELP5 glass were recorded in the wavelength region $550-850 \mathrm{~nm}$ at 393nm excitation wavelength and it is presented in Fig. 6. In Fig. 6, five emissions are detected and are at 578, 592, 613,652 \& 700 $\mathrm{nm}$ and are allocated to the transitions from ${ }^{5} \mathrm{D}_{0} \rightarrow{ }^{7} \mathrm{~F}_{0},{ }^{7} \mathrm{~F}_{1},{ }^{7} \mathrm{~F}_{2},{ }^{7} \mathrm{~F}_{3} \&{ }^{7} \mathrm{~F}_{4}$ respectively. Among these emissions $613 \mathrm{~nm}\left({ }^{5} \mathrm{D}_{0} \rightarrow{ }^{7} \mathrm{~F}_{2}\right)$ is more intense compare to other emission peaks. Hence it discloses red luminescence emission which can be used in display devices and red lasers [20].

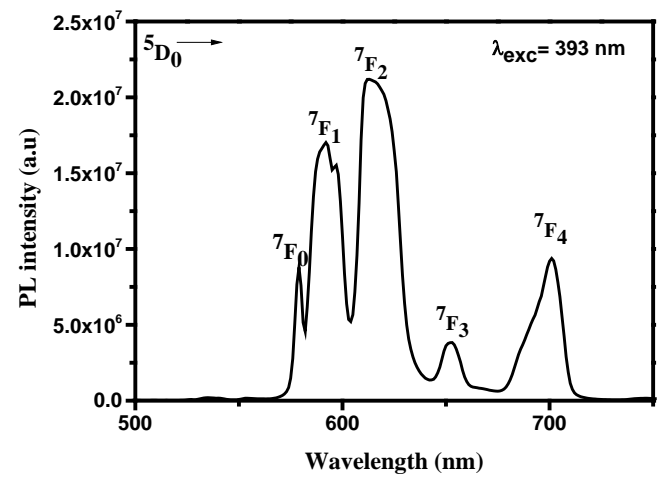

Figure 6. Emission spectrum at 393 excitation wavelength

\subsection{Judd-Ofelt analysis}

JO intensity parameters are essential to calculate the radiative parameters. The calculated JO intensity parameters with respect to europium concentration were tabulated in table 3 and also it is comparable with previously reported values. From the integrated areas of $\left({ }^{5} \mathrm{D}_{0} \rightarrow{ }^{7} \mathrm{~F}_{1}\right)$ to $\left({ }^{5} \mathrm{D}_{0} \rightarrow{ }^{7} \mathrm{~F}_{2}\right)$, the luminescence intensity ratio was estimated and these values are tabulated in table 3.

JO intensity parameters are generally estimated from the absorption spectrum, but in the case $\mathrm{Eu}^{3+}$ ion, it can be calculated from the luminescence spectra by intensity ratios of electric - dipole transition ${ }^{5} \mathrm{D}_{0} \rightarrow{ }^{7} \mathrm{~F}_{\mathrm{J}}(\mathrm{J}=2$ and 4) and magnetic - dipole transition ${ }^{5} \mathrm{D}_{0} \rightarrow{ }^{7} \mathrm{~F}_{1}[23,24]$. 
Table 3. J-O intensity parameters $\Omega_{2} \& \Omega_{4}\left(\times 10^{-20} \mathrm{~cm}^{2}\right)$ and intensity ratio of EuB glasses

\begin{tabular}{llll}
\hline Eu2O3 mol\% & $\mathbf{\Omega 2}$ & $\mathbf{\Omega 4}$ & Intensity ratio \\
\hline 0.1 & 5.89 & 4.82 & 2.214 \\
0.2 & 5.83 & 4.98 & 2.208 \\
0.3 & 5.58 & 4.98 & 2.004 \\
0.4 & 5.59 & 4.91 & 2.043 \\
0.5 & 5.29 & 4.69 & 1.834 \\
1 & 5.23 & 4.54 & 1.764 \\
1.5 & 5.07 & 4.24 & 1.649 \\
Eu3+:L5FBE & 5.64 & 4.44 & {$[21]$} \\
Eu(C2F5COO)3 & 4.42 & 2.07 & {$[22]$} \\
\hline
\end{tabular}

The J-O parameters $\Omega_{\mathrm{J}=2,4}$ were calculated using the following equation

$$
A_{0 \rightarrow J}=\frac{64 \pi^{3} e^{2} \chi}{3 h \lambda^{3} 4 \varepsilon_{0}} \sum_{J=2,4,6} \Omega_{2}<\psi_{J}\left\|U^{\lambda}\right\|^{2} \psi_{J}^{\prime},>^{2}
$$

where $\chi=n\left(n^{2}+2\right)^{2} / 9, \mathrm{n}$ is the refractive index, $\mathrm{e}$ is the charge of the electron, $\mathrm{h}$ is the Planck's constant, $\lambda$ is the wavelength of the particular transition, $\varepsilon_{0}$ is the permittivity of free space, $\Omega_{2} \& \Omega_{4}$ are the J-O intensity parameters used to describe the metal-ligand in the matrix and $\left\|U^{\lambda}\right\|^{2}$ is the square reduced matrix elements of the tensor operator.

The experimental coefficients of spontaneous emission $\left(A_{0 J}\right)$, are calculated by the relation

$$
A_{0 J}=A_{01}\left(\frac{I_{0 J}}{I_{01}}\right) \times\left(\frac{v_{01}}{v_{0 J}}\right)
$$

where $I_{0 \mathrm{~J}}$ is the maximum intensity of the $2^{\text {nd }}$ peak, $I_{01}$ is the maximum intensity of the $1^{\text {st }}$ peak, $v_{1}$ is the wavenumber of the $1^{\text {st }}$ peak, and $v_{2}$ is the wavenumber of the $2^{\text {nd }}$ peak.

J-O parameters $\Omega_{2}$ and $\Omega_{4}$ values are shown in table 3, the $\Omega_{2}$ and $\Omega_{4}$ values were decreases with the europium concentration. At $0.1 \mathrm{Eu}^{3+}$ concentration $\Omega_{2}$ value is more and it shows the existence of a covalent bond between the $\mathrm{Eu}^{3+}$ ion and their neighbouring ligands. Same variation is observed for both $\Omega_{2}$ and intensity ratio with the europium concentration. The radiative parameters were determined from JO theories like stimulated emission cross-sections, radiative lifetime, total transition probabilities, and effective bandwidth using the equations specified in reference [25, 26] and these values are tabulated in table 4 . The high value of stimulated emission is the most eye-catching features for the design and the growth of low-threshold and high gain laser applications. At $0.2 \mathrm{~mol} \%$ of europium the stimulated emission cross section value is high for the transition ${ }^{5} \mathrm{D}_{0} \rightarrow{ }^{7} \mathrm{~F}_{4}$ and it is well suitable lasing for action.

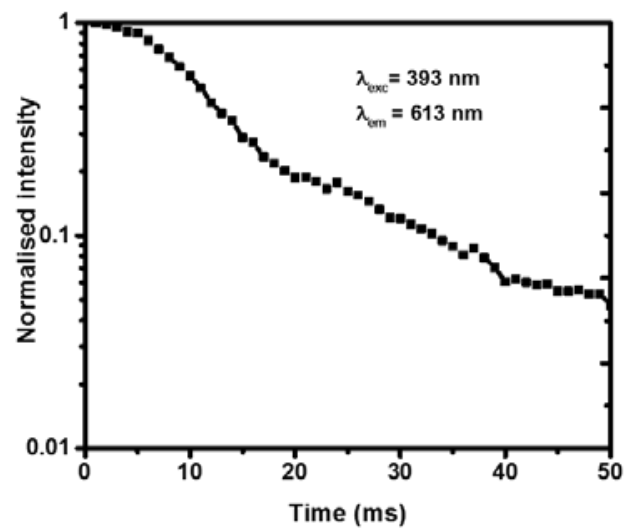

Figure 7. A typical time decay analysis of ELPB glass

\subsection{Decay analysis}

At $393 \mathrm{~nm}$ excitation wavelength the decay curves of $\left({ }^{7} \mathrm{~F}_{0} \rightarrow{ }^{5} \mathrm{~L}_{6}\right)$ transition of $\mathrm{Eu}^{3+}$ ion of ELPB ( 0.1, 0.2, 0.3, $0.4,0.5,1$ \& $1.5 \mathrm{~mol} \%)$ glasses were examined at $613\left({ }^{5} \mathrm{D}_{0} \rightarrow{ }^{7} \mathrm{~F}_{2}\right.$ transition $) \mathrm{nm}$ wavelength and a typical time decay graph is shown in figure 7 . The experimental lifetime $\left(\tau_{\exp }\right)$ decay values was evaluated for all the prepared 
glasses and the values are 3.38, 3.34, 3.27, 3.21, 3.16, 3.10 \& $3.05 \mathrm{~ms}$ for ELPB1, ELPB2, ELPB3, ELPB 4, ELPB5, ELPB6 \& ELPB7 respectively. The experimental lifetime values are seen to be decreasing with the Eu ${ }^{3+}$ ion concentration, and it shows the non-exponential behaviour of decay due to the non-radiative energy transfer between the $\mathrm{Eu}^{3+}$ ion in ELPB glasses. The quantum efficiency for ELPB1 \& ELPB2 are around 96-97\% and it is higher than the previous literature glasses [ 27-30].

$\mathrm{Eu}^{3+}$ ion doped lithium lead borate glasses are emitting red colour, this is recognized from the chromaticity diagram and it is shown in the figure 8 . The colour coordinates are $(0.623,0.324)(0.633,0.334),(0.623,0.324)$, (0.628, 0.325), (0.625, 0.323), (0.630, 0.330) \& (0.623, 0.324) for ELPB1, ELPB2, ELPB3, ELPB4, ELPB5, ELPB6 \& ELPB7 respectively. All the coordinates lie in the red region of CIE 1913 chromaticity diagram, which indicates that the prepared glass samples are well suitable for red-emitting devices.

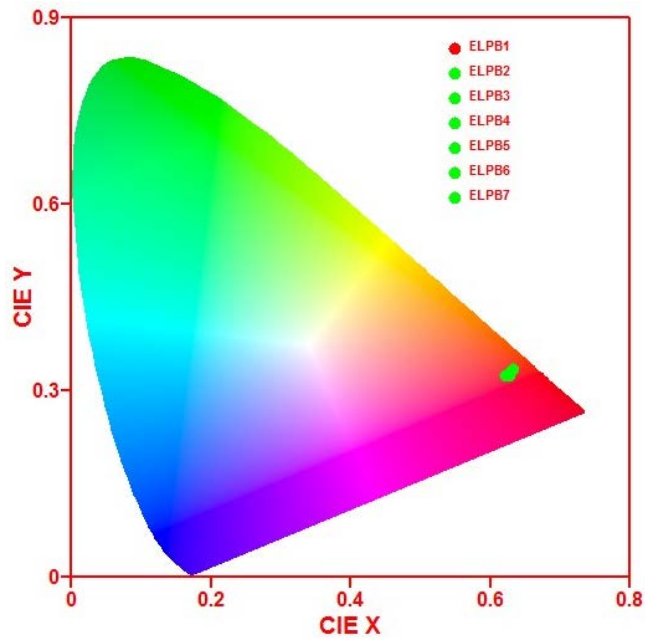

Figure 8. CIE diagram of ELPB glasses

Table 4. Emission wavelength $\left(\lambda_{\mathrm{p}}, \mathrm{nm}\right)$, Radiative transition probabilities $\left(\mathrm{A}_{\mathrm{R}}\right)$, Effective band width $\left(\Delta \lambda_{\text {eff, }} \mathrm{nm}\right)$, stimulated emission cross-section $\left(\sigma_{e} \times 10^{-22} \mathrm{~cm}^{2}\right)$, optical gain band width $\left(\sigma_{e} \times \Delta \lambda_{e f f} \times 10^{-34} \mathrm{~cm}^{3}\right)$ and radiative lifetime $\left(\tau_{\mathrm{r}} \mathrm{ms}\right)$ of $\mathrm{Eu}^{3+}$ doped different ELB glasses.

\begin{tabular}{|c|c|c|c|c|c|c|c|c|}
\hline Er2O3 mol\% & Parameter & ELPB1 & ELPB2 & ELPB3 & ELPB4 & ELPB5 & ELPB6 & ELPB7 \\
\hline \multirow{5}{*}{${ }^{5} \mathrm{D}_{0} \rightarrow{ }^{7} \mathrm{~F}_{1}$} & $\lambda p(n m)$ & 592 & 592 & 592 & 592 & 592 & 592 & 592 \\
\hline & $\mathbf{A}_{\mathbf{R}}$ & 50 & 50 & 50 & 50 & 50 & 50 & 50 \\
\hline & $\Delta \lambda_{\text {eff }}$ & 14.442 & 14.4365 & 14.874 & 14.630 & 15.318 & 15.739 & 16.298 \\
\hline & $\sigma_{e} \times 10^{-22} \mathrm{~cm}^{2}$ & 10.062 & 10.050 & 9.795 & 9.934 & 9.439 & 9.172 & 8.827 \\
\hline & $\sigma_{e} \times \Delta \lambda_{e f f} \times 10^{-28} \mathrm{~cm}^{3}$ & 14.531 & 14.508 & 14.569 & 14.533 & 14.458 & 14.435 & 14.386 \\
\hline \multirow[t]{5}{*}{${ }^{5} \mathrm{D}_{0} \rightarrow{ }^{7} \mathrm{~F}_{2}$} & $\lambda \mathbf{p}(\mathrm{nm})$ & 613 & 613 & 612 & 612 & 612 & 612 & 612 \\
\hline & $\mathbf{A}_{\mathbf{R}}$ & 106 & 103 & 88 & 89 & 72 & 69 & 60 \\
\hline & $\Delta \lambda_{\text {eff }}$ & 14.566 & 14.9481 & 16.2647 & 16.1800 & 18.684 & 19.349 & 21.523 \\
\hline & $\sigma_{e} \times 10^{-22} \mathrm{~cm}^{2}$ & 24.316 & 22.985 & 18.007 & 18.260 & 12.728 & 11.758 & 9.162 \\
\hline & $\sigma_{e} \times \Delta \lambda_{e f f} \times 10^{-28} \mathrm{~cm}^{3}$ & 35.418 & 34.358 & 29.288 & 29.544 & 23.781 & 22.750 & 19.719 \\
\hline \multirow[t]{5}{*}{${ }^{5} \mathrm{D}_{0} \rightarrow{ }^{7} \mathrm{~F}_{3}$} & $\lambda \mathbf{p}(\mathrm{nm})$ & 652 & 652 & 652 & 652 & 652 & 652 & 652 \\
\hline & $\mathbf{A}_{\mathrm{R}}$ & 0 & 0 & 0 & 0 & 0 & 0 & 0 \\
\hline & $\Delta \lambda_{\text {eff }}$ & 12.739 & 14.014 & 14.432 & 14.525 & 14.241 & 14.518 & 15.021 \\
\hline & $\sigma_{e} \times 10^{-22} \mathrm{~cm}^{2}$ & 0 & 0 & 0 & 0 & 0 & 0 & 0 \\
\hline & $\sigma_{e} \times \Delta \lambda_{e f f} \times 10^{-28} \mathrm{~cm}^{3}$ & 0 & 0 & 0 & 0 & 0 & 0 & 0 \\
\hline \multirow[t]{7}{*}{${ }^{5} \mathrm{D}_{0} \rightarrow{ }^{7} \mathrm{~F}_{4}$} & $\lambda p(n m)$ & 700 & 700 & 700 & 700 & 700 & 700 & 700 \\
\hline & $\mathbf{A}_{\mathbf{R}}$ & 130 & 135 & 135 & 133 & 127 & 123 & 115 \\
\hline & $\Delta \lambda_{\text {eff }}$ & 15.599 & 15.6296 & 15.831 & 15.986 & 16.788 & 17.0349 & 17.788 \\
\hline & $\sigma_{e} \times 10^{-22} \mathrm{~cm}^{2}$ & 47.351 & 48.995 & 48.575 & 47.271 & 42.765 & 40.749 & 36.363 \\
\hline & $\sigma_{e} \times \Delta \lambda_{e f f} \times 10^{-28} \mathrm{~cm}^{3}$ & 73.862 & 76.574 & 76.899 & 75.567 & 70.964 & 69.416 & 64.683 \\
\hline & $\tau_{\mathrm{rad}}$ & 3.496 & 3.472 & 3.663 & 3.676 & 4.016 & 4.132 & 4.444 \\
\hline & $\tau_{\exp }$ & 3.38 & 3.34 & 3.27 & 3.21 & 3.16 & 3.10 & 3.05 \\
\hline
\end{tabular}




\section{Conclusion}

Different concentration of $(0.1,0.2,0.3,0.4,0.5,1.0 \& 1.5)$ europium doped lithium lead borate glasses were prepared by melt quenching process. These prepared glass samples were characterized by DTA, FTIR, UVabsorption, luminescence, and time-decay measurements. From the DTA analysis, the glass transition, crystallization, and melting temperatures on the concentration of $\mathrm{Eu}_{2} \mathrm{O}_{3}$ were studied. The obtained results show good thermal stability, and it can be used in fibre fabrication. FTIR studies of the prepared glass samples show the functional groups present in the glass and the structural units. UV-optical absorption spectra show the rare-earth solubility, and optical energy bandgaps show the non-linear behaviour with the concentration of $\mathrm{Eu}_{2} \mathrm{O}_{3}$ due to the photon-lattice interaction. From luminescence spectra, the J-O parameters and intensity ratio were calculated. The intensity ratio ( $R$ ) and $\Omega_{2}$ are decreasing with the concentration of $\mathrm{Eu}_{2} \mathrm{O}_{3}$, and this shows the covalent bond around the $\mathrm{Eu}^{3+}$ ions. Radiative parameters like stimulated emission cross-section, optical gain bandwidths, optical gain, and a radiative lifetime of the prepared glasses were having been calculated. Among all the concentrations at Eu - $0.2 \mathrm{~mol} \%$ glass found larger stimulated emission cross-section $\left(48.995 \times 10^{-22} \mathrm{~cm}^{2}\right)$ for ${ }^{5} \mathrm{D}_{0} \rightarrow{ }^{7} \mathrm{~F}_{4}$ transition. The lifetime decay shows the tri-exponential nature for all the concentrations of $\mathrm{Eu}_{2} \mathrm{O}_{3}$. From the CIE diagram, it shows that the glass samples are emitting red colour, which is very close to standard red colour coordinates, which indicates that the newly prepared glass samples are emitting red colour, and it can be used in lasers.

\section{Reference}

[1] Lee YI, Lee JH, Hong SH, Park Y. Li-ion conductivity in $\mathrm{Li}_{2} \mathrm{O}-\mathrm{B}_{2} \mathrm{O}_{3}-\mathrm{V}_{2} \mathrm{O}_{5}$ glass system. Solid State Ionics. 2004;175:687-690.

[2] Wang Q, Yang B, Zhang Y, Xia H, Zhao T, Jiang H. High light yield $\mathrm{Ce}^{3+}$-doped dense scintillating glasses. Journal of Alloys and Compounds. 2013;581:801-804.

[3] Wang Q, Ouyang SY, Zhang WH, Yang B, Zhang YP, Xia HP. Luminescent properties and energy transfer mechanism of $\mathrm{Gd}^{3+}$ and $\mathrm{Eu}^{2+}$ co-doped phosphate glasses. Acta Metallurgica Sinica (English Letters). 2015;28(4):487-491.

[4] Day DE. Mixed alkali glasses—-their properties and uses. Journal of Non-Crystalline Solids. 1976;21(3):343372.

[5] Lavin V, Rodríguez-Mendoza UR, Martín IR, Rodríguez VD. Optical spectroscopy analysis of the Eu ${ }^{3+}$ ions local structure in calcium diborate glasses. Journal of Non-crystalline Solids. 2003;319:200-216.

[6] Linganna K, Jayasankar CK. Optical properties of Eu3+ ions in phosphate glasses. Spectrochimica Acta Part A: Molecular and Biomolecular Spectroscopy. 2012;97:788-797.

[7] Ratnakaram YC, Prasad VR, Babu S, Kumar VR. Luminescence performance of Eu ${ }^{3+}$-doped lead-free zinc phosphate glasses for red emission. Bulletin of Materials Science. 2016;39(4):1065-1072.

[8] Kiran N. $\mathrm{Eu}^{3+}$ ion doped sodium-lead borophosphate glasses for red light emission. Journal of Molecular Structure. 2014;1065:93-98.

[9] Mohan MM, Moorthy LR, Ramachari D, Jayasankar CK. Spectroscopic investigation and optical characterization of Eu3+ ions in K-Nb-Si glasses. Spectrochimica Acta Part A: Molecular and Biomolecular Spectroscopy. 2014;118:966-971.

[10] Davis EA, Mott N. Conduction in non-crystalline systems V. Conductivity, optical absorption and photoconductivity in amorphous semiconductors. Philosophical Magazine. 1970;22(179):903-922.

[11] Sharma V, Singh SP, Mudahar GS, Thind KS. Synthesis and characterization of cadmium containing sodium borate glasses. New J. Glass Ceram. 2012;2:150-155.

[12] Algradee MA, Sultan M, Samir OM, Alwany AE. Electronic polarizability, optical basicity and interaction parameter for $\mathrm{Nd}_{2} \mathrm{O}_{3}$ doped lithium-zinc-phosphate glasses. Applied Physics A. 2017;123(8):524.

[13] Pascuta P, Bosca M, Borodi G, Culea E. Thermal, structural and magnetic properties of some zinc phosphate glasses doped with manganese ions. Journal of Alloys and Compounds. 2011;509(11):4314-4319.

[14] Karthikeyan B, Mohan S. Structural, optical and glass transition studies on $\mathrm{Nd}^{3+}$-doped lead bismuth borate glasses. Physica B: Condensed Matter. 2003;334:298-302.

[15] Hrubý A. Evaluation of glass-forming tendency by means of DTA. Czechoslovak Journal of Physics B. 1972;22(11):1187-1193.

[16] Saad M, Poulin M. Glass forming ability criterion. Mater. Sci. Forum. 1987;19:11-18.

[17] Ouis MA, El-Batal HA, Azooz MA, Abdelghany AM. Characterization of WO3-doped borophosphate glasses by optical, IR and ESR spectroscopic techniques before and after subjecting to gamma irradiation. Indian J. Pure Appl. Phys. 2013; 51: 11-17.

[18] Lai YM, Liang XF, Yang SY, Wang JX, Cao LH, Dai B. Raman and FTIR spectra of iron phosphate glasses containing cerium. Journal of Molecular Structure. 2011;992:84-88. 
[19] Li YZ, Zhang QY, Shi DM, Qian Q, Xu SH. Enhanced 1.53- $\mu \mathrm{m}$ emission and lowered upconversion of Er3+doped gallate-lead-bismuth-germanium glass by rare-earth co-doping. Optical Materials. 2009;32(2):334338.

[20] Żur L. Structural and luminescence properties of Eu3+, Dy3+ and Tb3+ ions in lead germanate glasses obtained by conventional high-temperature melt-quenching technique. Journal of Molecular Structure. 2013;1041:50-54.

[21] Babu P, Jayasankar CK. Optical spectroscopy of Eu3+ ions in lithium borate and lithium fluoroborate glasses. Physica B: Condensed Matter. 2000;279(4):262-281.

[22] She J, Li D. Synthesis and optical properties of europium pentafluoropropionate 1, 10-phenanthroline complex and its silica glass. Frontiers of Optoelectronics in China. 2011;4(4):382-386.

[23] Werts MH, Jukes RT, Verhoeven JW. The emission spectrum and the radiative lifetime of Eu3+ in luminescent lanthanide complexes. Physical Chemistry Chemical Physics. 2002;4(9):1542-1548.

[24] Prasannakumar JB, Vidya YS, Anantharaju KS, Ramgopal G, Nagabhushana H, Sharma SC, Prasad BD, Prashantha SC, Basavaraj RB, Rajanaik H, Lingaraju K. Bio-mediated route for the synthesis of shape tunable $\mathrm{Y}_{2} \mathrm{O}_{3}: \mathrm{Tb}^{3+}$ nanoparticles: photoluminescence and antibacterial properties. Spectrochimica Acta Part A: Molecular and Biomolecular Spectroscopy. 2015;151:131-140.

[25] Som S, Mitra P, Kumar V, Kumar V, Terblans JJ, Swart HC, Sharma SK. The energy transfer phenomena and colour tunability in $\mathrm{Y}_{2} \mathrm{O}_{2} \mathrm{~S}$ : Eu3+/Dy3+ micro-fibers for white emission in solid state lighting applications. Dalton Transactions. 2014;43(26):9860-9871.

[26] Damodaraiah S, Prasad VR, Lakshmi RV, Ratnakaram YC. Luminescence behaviour and phonon sideband analysis of europium doped $\mathrm{Bi} 2 \mathrm{O} 3$ based phosphate glasses for red emitting device applications. Optical Materials. 2019;92:352-358.

[27] Suthanthirakumar P, Arunkumar S, Marimuthu K. Investigations on the spectroscopic properties and local structure of Eu3+ ions in zinc telluro-fluoroborate glasses for red laser applications. Journal of Alloys and Compounds. 2018;760:42-53.

[28] Swapna K, Mahamuda S, Rao AS, Sasikala T, Packiyaraj P, Moorthy LR, Prakash GV. Luminescence characterization of Eu3+ doped Zinc Alumino Bismuth Borate glasses for visible red emission applications. Journal of Luminescence. 2014;156:80-86.

[29] Deopa N, Kaur S, Prasad A, Joshi B, Rao AS. Spectral studies of Eu3+ doped lithium lead alumino borate glasses for visible photonic applications. Optics \& Laser Technology. 2018;108:434-440.

[30] Anjaiah G, Rasool SN, Kistaiah P. Spectroscopic and visible luminescence properties of rare earth ions in lead fluoroborate glasses. Journal of Luminescence. 2015;159:110-118.

(C) 2020 by the author(s). This work is licensed under a Creative Commons Attribution 4.0 International License (http://creativecommons.org/licenses/by/4.0/). Authors retain copyright of their work, with first publication rights granted to Tech Reviews Ltd. 